\title{
Correction to: Non-invasive assessment of plasma parameters inside an ion thruster combining optical emission spectroscopy and principal component analysis
}

\author{
Benny T. Nauschütt ${ }^{1 *}$, Limei Chen ${ }^{1}$, Kristof Holste ${ }^{1}$ and Peter J. Klar ${ }^{1}$
}

The original article can be found online at https://doi.org/10.1140/ epjti/s40485-021-00070-x

\section{"Correspondence:}

Benny.Nauschuett@physik.uni -giessen.de

${ }^{1}$ Institute of Experimental Physics I, Justus Liebig University, Heinrich-Buff-Ring 16, 35392 Giessen, Germany

\section{Springer}

Correction to: EPJ Techn Instrum 8, 13 (2021). https://doi.org/10.1140/epjti/s40485-02100070-x.

In the publication of the article [1], the principle component analysis section contains mixed up indices. The corrected part of the affected section is shown below.

\section{Corrected}

First, the average spectrum of the entire reference data set $\overline{S_{\mathrm{PCA}}}(\lambda)$ is subtracted from each spectrum $S(\lambda)$. To derive the new coordinates, i.e., the PCA-axes, the covariances $\sigma_{i j}$ of each of the $n$ wavelength positions with every other wavelength position (including itself) are calculated using

$$
\sigma_{i j}=\frac{1}{m} \cdot \sum_{k=0}^{m}\left(x_{k i}-\overline{x_{i}}\right) \cdot\left(x_{k j}-\overline{x_{j}}\right) \quad \text { where } \overline{x_{i}}=\overline{x_{j}}=0
$$

Here, $x_{k i}$ and $x_{k j}$ are the values of wavelength positions $i$ and $j$ of the spectrum $k$. Since the average intensities of each wavelength position $\overline{x_{i}}$ and $\overline{x_{j}}$ were already subtracted before, they are now zero.

With these covariances the covariance matrix $\mathbf{C}$ is set up

$$
\mathbf{C}=\left(\begin{array}{cccc}
\sigma_{00} & \sigma_{01} & \cdots & \sigma_{0 n} \\
\sigma_{10} & \sigma_{11} & \cdots & \sigma_{1 n} \\
\vdots & \vdots & \ddots & \vdots \\
\sigma_{n 0} & \sigma_{n 1} & \cdots & \sigma_{n n}
\end{array}\right)
$$

All the changes that were requested are implemented in this correction and the original article [1] has been corrected.

(c) The Author(s) 2021. This article is licensed under a Creative Commons Attribution 4.0 International License, which permits use, sharing, adaptation, distribution and reproduction in any medium or format, as long as you give appropriate credit to the original author(s) and the source, provide a link to the Creative Commons licence, and indicate if changes were made. The images or other third party material in this article are included in the article's Creative Commons licence, unless indicated otherwise in a credit line to the material. If material is not included in the article's Creative Commons licence and your intended use is not permitted by statutory regulation or exceeds the permitted use, you will need to obtain permission directly from the copyright holder. To view a copy of this licence, visit http://creativecommons.org/licenses/by/4.0/. 


\section{Publisher's Note}

Springer Nature remains neutral with regard to jurisdictional claims in published maps and institutional affiliations.

Published online: 09 December 2021

\section{References}

1. Nauschütt BT, Chen L, Holste K, Klar PJ. Non-invasive assessment of plasma parameters inside an ion thruster combining optical emission spectroscopy and principal component analysis. EPJ Tech Instrum. 2021;8(1). https://doi.org/10.1140/epjti/s40485-021-00070-x 